Article

\title{
An Experimental Study on the Effect of Multiple Lightning Waveform Parameters on the Aging Characteristics of $\mathrm{ZnO}$ Varistors
}

\author{
Chunlong Zhang ${ }^{1,2,3,4}$, Chunying $\mathrm{Li}^{3,4}$, Dongbo $\mathrm{Lv}^{3,4}$, Hao Zhu ${ }^{3,5}$ and Hongyan Xing ${ }^{1,2,3, *(1)}$ \\ 1 Collaborative Innovation Center on Forecast and Evaluation of Meteorological Disasters, \\ Nanjing University of Information Science \& Technology, Nanjing 210044, China; \\ 20151114051@nuist.edu.cn \\ 2 Jiangsu Key Laboratory of Meteorological Observation and Information Processing, \\ Nanjing University of Information Science \& Technology, Nanjing 210044, China \\ 3 School of Atmospheric Physics, Nanjing University of Information Science \& Technology, \\ Nanjing 210044, China; 20156282032@nuist.edu.cn (C.L.); 20156282031@nuist.edu.cn (D.L.); \\ 20156282035@nuist.edu.cn (H.Z.) \\ 4 Heilongjiang Meteorological Disaster Prevention Technology Center, Harbin 150030, China \\ 5 Anhui Meteorological Disaster Prevention Center, Hefei 230061, China \\ * Correspondence: xinghy@nuist.edu.cn; Tel.: +86-025-58731370
}

Received: 7 April 2020; Accepted: 1 June 2020; Published: 3 June 2020

\begin{abstract}
In this study, in order to study the effect of multi-pulse waveform parameters on the aging characteristics of $\mathrm{ZnO}$ varistor, the aging rate and surface temperature rise of $\mathrm{ZnO}$ varistor under the impact of multi-pulse current were analyzed. The number of pulses and the pulse interval under multiple pulses play a decisive role in the aging rate of $\mathrm{ZnO}$ varistor. The greater the number of pulses and the smaller the pulse interval, the higher the temperature rise of the $\mathrm{ZnO}$ varistor and the faster the aging rate, the more likely to be failure and damage. The surface temperature distribution of the $\mathrm{ZnO}$ varistor under multi-pulse is not uniform, and the more pulses, the more uneven the temperature distribution, but the surface temperature rise has a nonlinear relationship with the number of pulses. The relationship between pulse interval, impact times and average surface temperature rise is established. The aging mechanism of the $\mathrm{ZnO}$ varistor under a multi-pulse lightning stroke was revealed from the perspective of energy absorption and heat transfer modelling. The energy sustained by the $\mathrm{ZnO}$ varistor under multiple pulses have a nonlinear multiple relationship with the energy of the single pulse current wave at the same amplitude. The superimposed cumulative energy of the impact under multiple pulses accelerates the aging process of the $\mathrm{ZnO}$ varistor, and eventually produces an irreversible structural destruction.
\end{abstract}

Keywords: aging characteristics; impulse current; multiple lightning; $\mathrm{ZnO}$ varistors; energy absorption

\section{Introduction}

The installation of a surge protector (SPD) is one of the most economical and effective protection methods for reducing the damage of lightning strikes in low-voltage power distribution systems. As the core component of the $\mathrm{ZnO}$ varistor, it has good nonlinearity, low residual voltage and rapid response. Its advantages include achieving lightning protection for electronic and electrical equipment by limiting overvoltage and discharge surge current [1-3]. At present, SPDs produced in various countries around the world are basically developed and produced in accordance with the technical standards of single-pulse products, and are tested by the lightning high-voltage laboratory, using $10 / 350 \mu \mathrm{s}$ or $8 / 20 \mu$ s single-pulse waveforms. Although many lightning protection products of low-voltage 
power distribution systems have passed tests according to technical standards, protection failure often occurs when lightning strikes, and fire accidents may even occur. The data collected by modern lightning observations and collected by artificial lightning shows that $80 \%$ of the lightning in nature is multi-pulse. The traditional single-pulse test cannot effectively reflect the performance change of SPD subjected to natural multi-pulse lightning strikes, which leads to the lightning test deviating from the real lightning discharge process.

The problem of lightning strike failure of $\mathrm{ZnO}$ varistor has always been one of the core problems of lightning protection in low-voltage distribution systems. It is an important means of improving the safety performance of $\mathrm{ZnO}$ varistors by studying the lightning strike failure characteristics and failure mechanism of $\mathrm{ZnO}$ varistors through laboratory simulation of natural lightning strikes [4,5]. The damage characteristics and aging mechanism of $\mathrm{ZnO}$ varistor under multi-pulse is very important to study the failure mode of SPD. Compared with single pulse, $\mathrm{ZnO}$ varistor is aggravated by the thermal effect under multi-pulse current impact. Changes, impact resistance and other aspects will face more severe tests.

In recent years, with the deepening of people's understanding of the physical characteristics of multi-pulse lightning, domestic and foreign scholars have made some achievements in the study of the damage and aging mechanism of $\mathrm{ZnO}$ varistor under multi-pulse, but they are not systematic and in-depth.

Darveniza et al. [6,7] carried out a series of studies on the destruction effect of multi-pulse lightning strikes on $\mathrm{ZnO}$ varistor in power distribution system in 1993, and judged the ZnO varistor by analyzing the rate of change of varistor voltage change ratio before and after impact. At the same time, it proposed that multi-pulse test methods should be added to the lightning test technical standards. High-speed camera and microscopic electron microscope scanning can be used to analyze the electrical properties of $\mathrm{ZnO}$ varistor. Through high-speed camera shooting, it was found that the $\mathrm{ZnO}$ varistor will experience flashover after being subjected to multi-pulse lightning strikes. The electrical parameters of the $\mathrm{ZnO}$ varistor will change significantly. Microscopic electron microscopy scanning can find changes in the internal structure.

Electrical parameters and changes in the microstructure and performance of the multi-pulse $\mathrm{ZnO}$ varistor were analyzed in two ways, but the damage and aging mechanism of the $\mathrm{ZnO}$ varistor was not analyzed [8,9]. Rousseau A et al. [10] pointed out in a report on the 2014 International Conference on Lightning Protection (ICLP), held in Shanghai, that the design and production process of $\mathrm{ZnO}$ varistors have an important impact on their ability to withstand multi-pulse shocks, but the report did not give details on the material and structural factors of impact capability. By changing the temperature and humidity of $\mathrm{ZnO}$ varistors, some scholars found that the aging rate of a wet $\mathrm{ZnO}$ varistor under multi-pulse impact is significantly faster than that under dry conditions. Increased humidity will accelerate the aging rate, indicating that the environmental conditions of temperature and humidity are important factors affecting the aging of a $\mathrm{ZnO}$ varistor [11-13].

In 2011, C. de Salles [14] applied a series of shock pulses to $\mathrm{ZnO}$ varistors at different temperatures, and compared the leakage current and power loss of each pulse when the $\mathrm{ZnO}$ varistor reached room temperature. After statistical analysis, it was proposed that aging is related to the number of pulses applied, but there is no quantitative analysis of the relationship between aging and temperature and pulse energy absorption. B. Vahidi [15] and C. Heinrich [16], respectively, explained the destructive effects of multi-pulse lightning strikes on $\mathrm{ZnO}$ arresters in the power distribution system at the 24th International Conference on Lightning Protection. Haryono T et al. $[17,18]$ conducted an impact experiment on a $\mathrm{ZnO}$ varistor using an 8/20 $\mu$ s impulse current with five pulses and a pulse interval of $35 \mathrm{~ms}$. This increases the probability of damage. This phenomenon also exists under single pulse impact, because the amplitude of the injected lightning current is proportional to the impact energy. A large current amplitude will inevitably make the $\mathrm{ZnO}$ varistor have a higher temperature rise. However, the damage result of the $\mathrm{ZnO}$ varistor is not related to the thermal effect of multi-pulse lightning current. 
In the above study of the aging law and mechanism, the influence of waveform parameters, such as pulse interval, on the temperature rise and aging rate of the $\mathrm{ZnO}$ varistor was not analyzed. For the energy absorption capacity of the $\mathrm{ZnO}$ varistor under a single pulse, only the amplitude of the current needs to be considered, that is, the ultimate current strength that can be withstood [19]. Compared with the single pulse, the multi-pulse has different waveform parameters, such as different pulse number and pulse interval. The change of each factor may change the energy value applied to the $\mathrm{ZnO}$ varistor. The resulting temperature rise and the degree of damage are also different, so it is necessary to study the effect of different waveform parameters on the aging characteristics of the $\mathrm{ZnO}$ varistor under pulse. In this paper, the controlled variable method is used to study the effect of multi-pulse waveform parameters, such as the number of pulses, pulse interval and number of impacts on the aging rate of the $\mathrm{ZnO}$ varistor, and its relationship with the surface temperature rise. It further reveals, from the perspective of energy absorption, the aging mechanism of the $\mathrm{ZnO}$ varistor under pulsed lightning.

\section{Experiment}

\subsection{Impulse Test and Waveform}

The experimental platform built in this paper can produce a lightning strike process similar to or similar to the natural lightning in the laboratory environment. It is used in multi-pulse lightning shock test experiments. The impact test platform is shown in Figure 1.

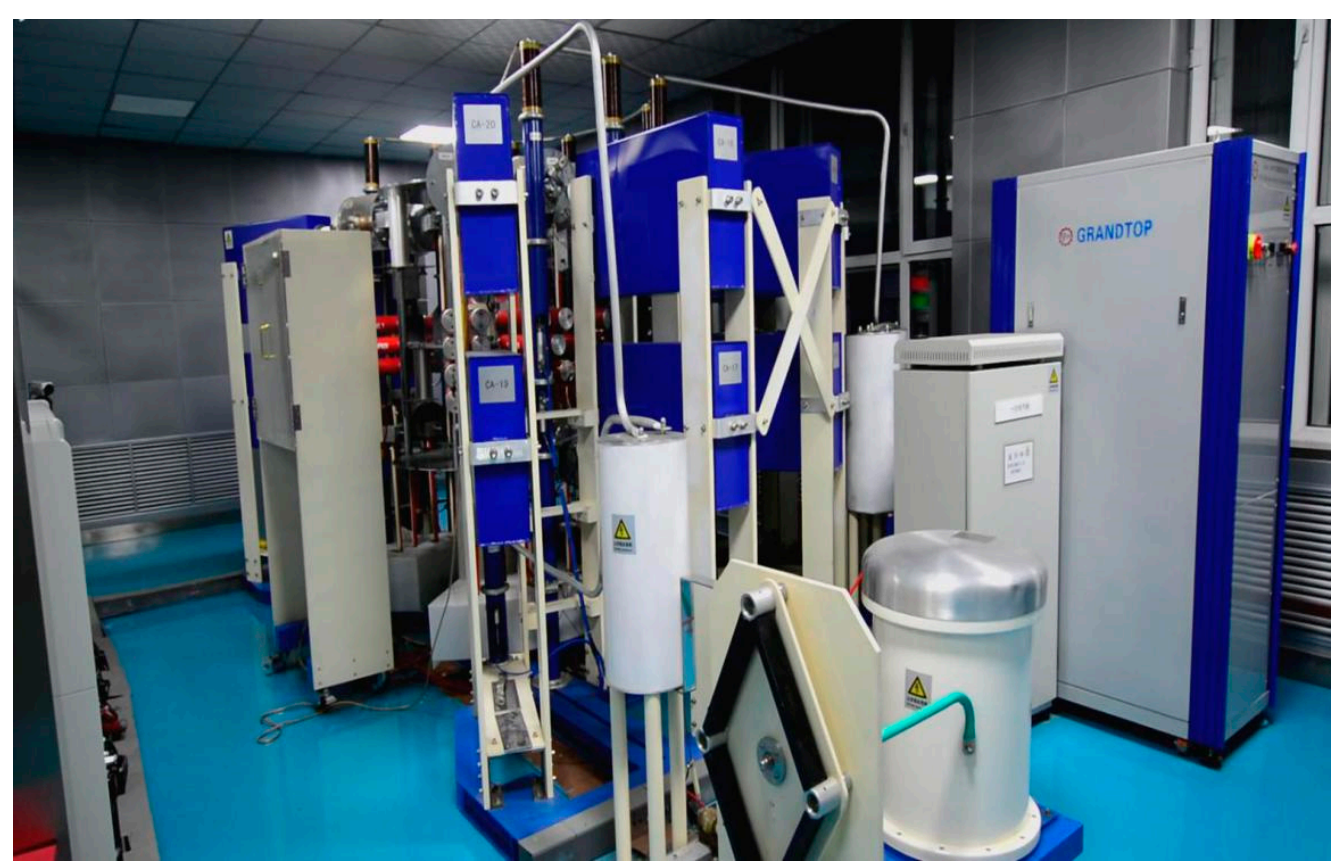

Figure 1. A 20-pulse lightning impulse current generator.

The main technical parameter design of the multi-pulse lightning test device is shown in Table 1.

The high-voltage ignition device is a key device for realizing pulse triggering, and is composed of a pulse controllable timer, pulse polarity control, a pulse silicon stack trigger, a pulse spark plug and a pulse booster. The synchronous trigger ( $0 \mu \mathrm{s})$ or asynchronous trigger ( $1 \mu \mathrm{s}-999 \mathrm{~ms})$ time command is sent to the pulse controllable timer through the 232 communication protocol. The pulse controllable timer sends out 20 pulse trigger signals. After photoelectric conversion, it is connected to the trigger box through the optical fiber line with the transmitting head and the receiving head, and the booster generates a high voltage. The pulse silicon stack trigger triggers the conducting silicon stack respectively, and the current after the output triggers is boosted. The device reaches a high voltage capable of ionizing air and conducts to the spark plug. The high voltage is discharged through the 
discharge electrode after breaking through a certain thickness of air, thereby completing a multi-pulse discharge ignition.

Table 1. The main technical parameters of the experimental setup.

\begin{tabular}{ccc}
\hline No. & Technical Parameters & Technical Index \\
\hline 1 & Charging device input power & $220 \mathrm{~V} / 40 \mathrm{kV} / 80 \mathrm{kV}$ \\
2 & Charging voltage & $80 \mathrm{kVDC} \pm 10 \%$ \\
3 & Maximum charging current & $1 \mathrm{~A}$ \\
4 & Pulse capacitor & $40 \mathrm{kV} / 16 \mu \mathrm{F}$ \\
5 & Total pulse energy & $240 \mathrm{~kJ}$ \\
6 & $8 / 20 \mu$ s output maximum current & $150 \mathrm{kA}$ \\
7 & Trigger gap voltage range & $5 \mathrm{kV}-120 \mathrm{kV}$ \\
8 & Trigger time controllable accuracy & $\pm 1 \mu \mathrm{s}$ \\
9 & Trigger delay range & $0-999 \mathrm{~ms}$ \\
\hline
\end{tabular}

The main body of the multi-pulse lightning experiment platform is an impulse current generator. The basic principle is to connect multiple capacitors in series and parallel, charge them through a high-voltage DC device through rectified voltage or constant current, and then generate a large current to $\mathrm{ZnO}$ through gap discharge. Figure 2 shows the basic circuit of the inrush current generator. $L$ and $R$ are the total inductance and resistance of all devices; $C$ is the total capacitance of multiple capacitors connected in parallel; $D$ is the silicon stack; $G$ is the ignition discharge ball gap; $C R O$ is the measurement oscilloscope; $T$ is the charging transformer; $O$ is test terminal sample; $r$ is protection resistance; $S$ is shunt for measuring sample current; $C 1$ and $C 2$ are voltage dividers for measuring sample voltage. When the circuit is running, the rectifier device is charged and transported, according to the voltage required by the capacitor bank, and, at the same time, sends a trigger pulse to penetrate the ball gap $G$, and the capacitor bank can be discharged on $L, R$ and the sample.

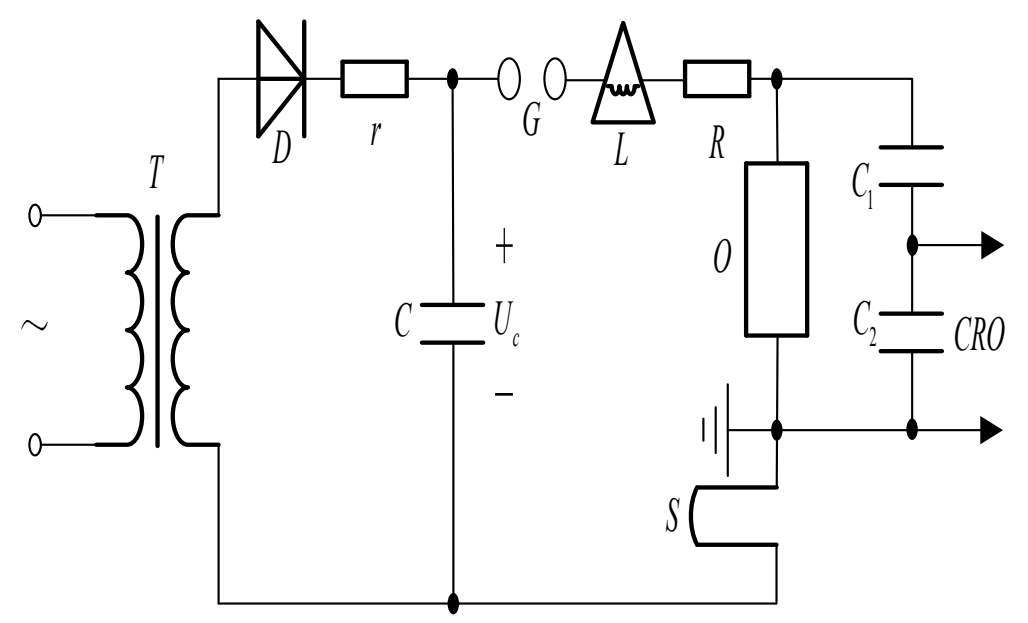

Figure 2. Basic circuit of an inrush current generator.

At present, in the international multi-pulse lightning observation record, the maximum number of pulses does not exceed 20, so, in this paper, the lightning impulse test platform is developed according to the maximum number of pulses in the research process. The 20-pulse lightning current waveform collected by the oscilloscope is shown in Figure 3, which can clearly display the waveform shape of the multi-pulse. The number of pulses is 20. 


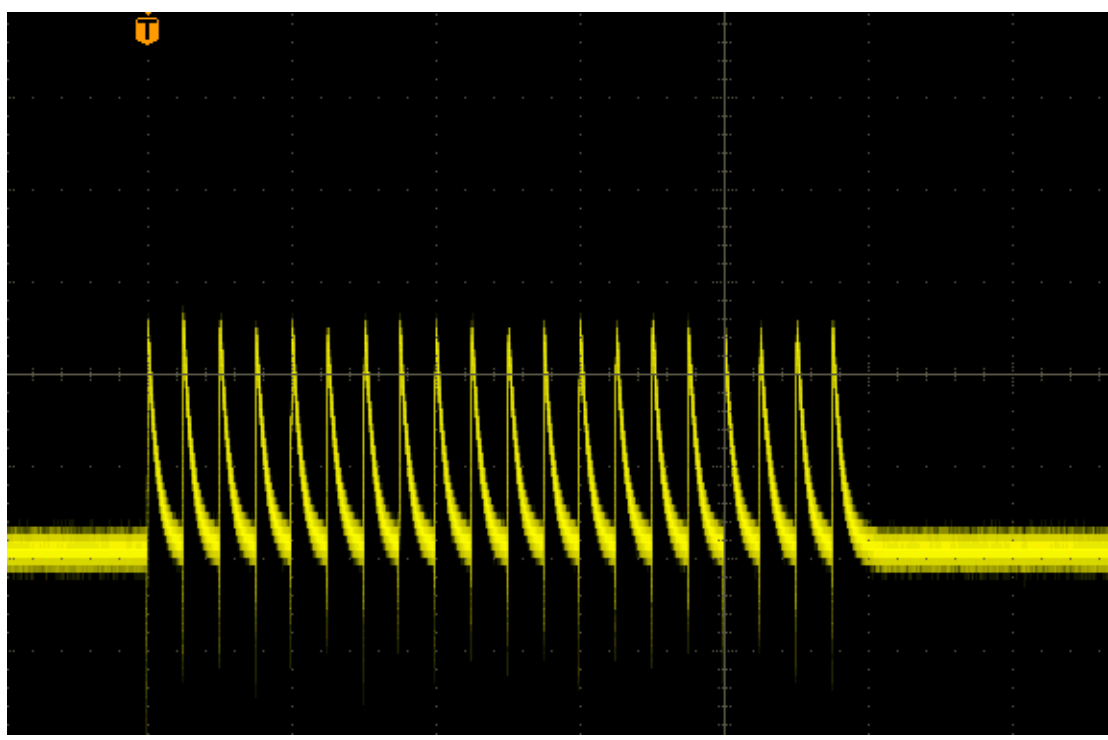

Figure 3. A 20 pulse lightning waveform.

\subsection{Sample Preparation}

In the experiment, the same batch of $\mathrm{ZnO}$ varistor square sheets from a certain manufacturer was selected. The nominal discharge current of the sample was $20 \mathrm{kA}$, the maximum discharge current was $40 \mathrm{kA}$, and the maximum continuous operating voltage was $385 \mathrm{~V}$. The static parameters of the varistor voltage and leakage current were measured and selected A sample with the closest static parameters and electrical characteristics was used as the test product. The varistor voltage $\mathrm{U}_{1 \mathrm{~mA}}$ is between $680 \mathrm{~V}$ and $690 \mathrm{~V}$, and the leakage current $I_{\mathrm{ie}}$ is $0.1 \mu \mathrm{A}$. The samples were numbered P1-P18, every three samples are a group and different numbers correspond to different test waveforms, as shown in Table 2. $\mathrm{P} 1-\mathrm{P} 12$ are the experimental samples used for the aging of $\mathrm{ZnO}$ varistors with different pulse time intervals. The number of pulses is 5, and the pulse interval $\Delta t$ is $20 \mathrm{~ms}, 50 \mathrm{~ms}, 100 \mathrm{~ms}$ and $500 \mathrm{~ms}$, respectively. The P6 sample corresponds to a pulse interval of $50 \mathrm{~ms}$, the P7-P9 sample corresponds to a pulse interval of $100 \mathrm{~ms}$ and the P10-P12 sample corresponds to a pulse interval of $500 \mathrm{~ms}$. P13-P18 are the experimental samples used for the aging of $\mathrm{ZnO}$ varistors with different pulse numbers. The pulse interval is $50 \mathrm{~ms}$, P13-P15 samples correspond to 3 pulses, P16-P18 samples correspond to 4 pulses.

Table 2. The static parameters of different samples and the corresponding impulse current waveform parameters.

\begin{tabular}{ccccc}
\hline No. & Initial $\mathbf{U}_{\mathbf{1 ~ m A}}(\mathrm{V})$ & Initial $\boldsymbol{I}_{\text {ie }}(\boldsymbol{\mu} \mathbf{A})$ & $\boldsymbol{n}$ & $\boldsymbol{\Delta} \boldsymbol{t}(\mathrm{ms})$ \\
\hline P1 & 682 & 0.1 & & \\
P2 & 680 & 0.1 & 5 & 20 \\
P3 & 687 & 0.1 & & \\
P4 & 686 & 0.1 & & \\
P5 & 688 & 0.2 & 5 & 50 \\
P6 & 686 & 0.1 & & \\
P7 & 687 & 0.1 & & \\
P8 & 687 & 0.1 & 5 & 100 \\
P9 & 682 & 0.1 & & \\
P10 & 684 & 0.1 & & \\
P11 & 683 & 0.1 & 5 & 500 \\
P12 & 665 & 0.1 & & \\
P13 & 690 & 0.1 & & \\
P14 & 690 & 0.1 & 3 & 50 \\
P15 & 690 & 0.1 & & \\
P16 & 688 & 0.1 & & \\
P17 & 689 & 0.1 & 4 & 50 \\
P18 & 689 & 0.1 & & \\
\hline
\end{tabular}




\subsection{Experimental Procedure}

The test procedure is carried out according to the limited voltage impulse test item of IEC61643. The waveform parameters are designed according to the lightning multi-pulse waveform parameters specified in IEC62305-1. The flowchart of the experimental procedure is shown in Figure 4.

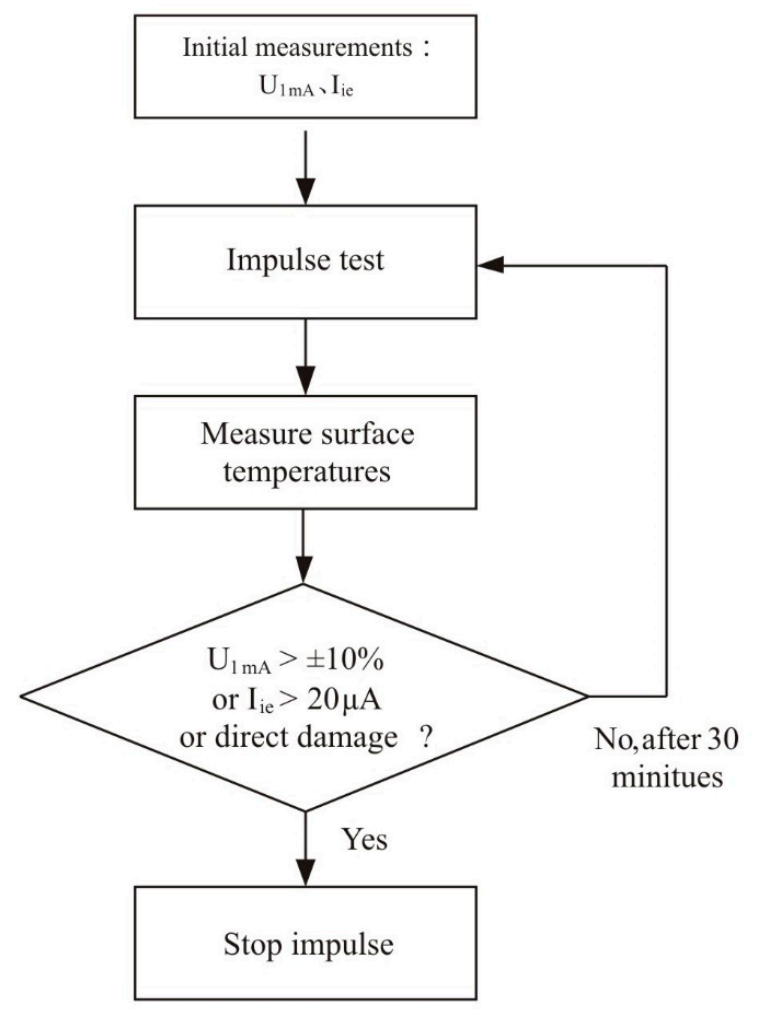

Figure 4. Flowchart of the experimental procedure.

(1) Initial measurements: the samples are characterized with the $\mathrm{U}_{1 \mathrm{~mA}}, I_{\mathrm{ie}}$, and by photographs taken at the beginning of the test.

(2) Impulse test: adjust the charging voltage of the impulse current generator, so that it can output the current amplitude that meets the experiment. A multi-pulse lightning current is used to perform an impact test on a $\mathrm{ZnO}$ varistor. Taking a 5-pulse impact with a pulse interval of $50 \mathrm{~ms}$ as an example, every 5 pulse currents are recorded as a group of impulse current. After cooling for $30 \mathrm{~min}$, the next group of impulse current was performed. The impact time interval between each two adjacent groups is $30 \mathrm{~min}$. This time interval is sufficient to allow the $\mathrm{ZnO}$ varistor to cool to room temperature before the next impact. Until the static parameter of the $\mathrm{ZnO}$ varistor changes in $\mathrm{U}_{1 \mathrm{~mA}}$, by more than $\pm 10 \%$, or $I_{\mathrm{ie}}$ exceeds $20 \mu \mathrm{A}$ or the appearance damage occurs directly, the $\mathrm{ZnO}$ varistor is judged to be invalid, the impact test is stopped, and the relevant data is recorded. Finally, the static parameters of the sample after different multi-pulse intervals $\Delta t$ and $n$ are obtained.

(3) Measure the temperature distribution of the sample surface after each impact. Figure 5 is the auxiliary experimental equipment. Figure $5 \mathrm{a}$ is an infrared thermometer, used to measure whether the sample reaches the cooling temperature, model is FLUKE63; Figure $5 \mathrm{~b}$ is an infrared thermal imager, used to measure the surface temperature distribution of the sample after impact, model FLUKE TiS2; Figure $5 \mathrm{c}$ is the varistor tester, used to measure the static parameters of the sample before and after impact, the model is FC-2GA; Figure 5d is the LCR tester, used to measure the resistance of the sample before and after impact, the model is HIOKIIM3523.

(4) Change the pulse interval and the number of pulses, repeat the impact experiment process in (2), and record the relevant data. The specific pulse number and pulse interval are shown in Table 1. 

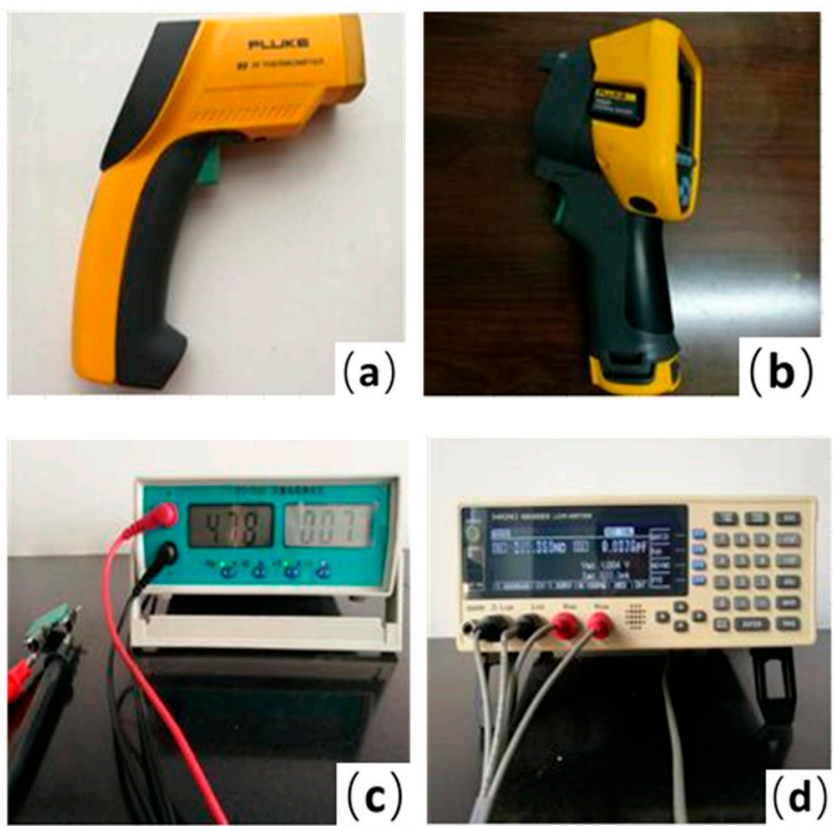

Figure 5. Experimental auxiliary measuring equipment. (a) Infrared thermometer, (b) Infrared thermal imager, (c) Varistor tester, (d) LCR tester.

\section{Results and Discussion}

\subsection{Effect of Multi-Pulse Waveform Parameters on Electrical Performance Parameters of $\mathrm{ZnO}$ Varistor}

The static parameters of the $\mathrm{ZnO}$ varistor after the pulse is impacted at different pulse intervals under five pulses are shown in Table 3. The P1-P3 sample can withstand 14 shocks after a pulse interval of $20 \mathrm{~ms}$, the minimum varistor voltage is $615 \mathrm{~V}$, and the maximum leakage current is $12.6 \mu \mathrm{A}$. The P4-P6 sample can withstand 15 shocks after a pulse interval of $50 \mathrm{~ms}$, the minimum varistor voltage is $620 \mathrm{~V}$, and the maximum leakage current is $9.9 \mu \mathrm{A}$. The P7-P9 samples can withstand 16 shocks after a pulse interval of $100 \mathrm{~ms}$, the minimum varistor voltage is $625 \mathrm{~V}$, and the maximum leakage current is $7.4 \mu \mathrm{A}$. The P10-P12 sample can withstand 17 shocks after a pulse interval of $500 \mathrm{~ms}$, the minimum varistor voltage is $628 \mathrm{~V}$, and the maximum leakage current is $6.2 \mu \mathrm{A}$.

Table 3. The electrical parameters after impulse at different pulse intervals.

\begin{tabular}{cccccccc}
\hline No. & $\boldsymbol{n}$ & $\mathbf{U}_{\mathbf{1} \mathbf{~ m A}}(\mathbf{V})$ & $\boldsymbol{I}_{\mathbf{i e}}(\boldsymbol{\mu} \mathbf{A})$ & No. & $\boldsymbol{n}$ & $\mathbf{U}_{\mathbf{1 ~ m A}}(\mathbf{V})$ & $\boldsymbol{I}_{\mathbf{i e}}(\boldsymbol{\mu A})$ \\
\hline P1 & 14 & 610 & 12.6 & P7 & 15 & 625 & 7.0 \\
P2 & 14 & 611 & 11.9 & P8 & 15 & 624 & 7.2 \\
P3 & 14 & 610 & 12.3 & P9 & 16 & 625 & 7.4 \\
P4 & 15 & 615 & 8.9 & P10 & 17 & 628 & 6.2 \\
P5 & 15 & 614 & 9.9 & P11 & 17 & 628 & 6.1 \\
P6 & 16 & 612 & 9.3 & P12 & 17 & 629 & 5.8 \\
\hline
\end{tabular}

As shown in Table 2, it can be found that, under the impact of five pulses and amplitude of $20 \mathrm{kA}$, the pulse interval length has an effect on the number of $\mathrm{ZnO}$ varistors' impact resistance. It shows that different pulse time intervals have an effect on the performance of a $\mathrm{ZnO}$ varistor.

Taking the leakage current parameter in the static parameter as an example, the influence of the pulse interval and the number of pulses on the electrical performance of the $\mathrm{ZnO}$ varistor under multi-pulse impact is analyzed. Studies have shown that the leakage current of $\mathrm{ZnO}$ varistors increases slowly under a single pulse impact test. Figure 6 shows the change trend of leakage current, with the number of impacts under four pulse intervals of $20 \mathrm{~ms}, 50 \mathrm{~ms}, 100 \mathrm{~ms}$ and $500 \mathrm{~ms}$. It can be seen that 
under multi-pulse impact, the leakage current of $\mathrm{ZnO}$ varistor increases, until it deteriorates. The trend of the change curve at different intervals tends to be the same, but the shorter the pulse time interval, the faster the leakage current changes. This shows that the pulse interval is an important indicator that affects the aging rate.

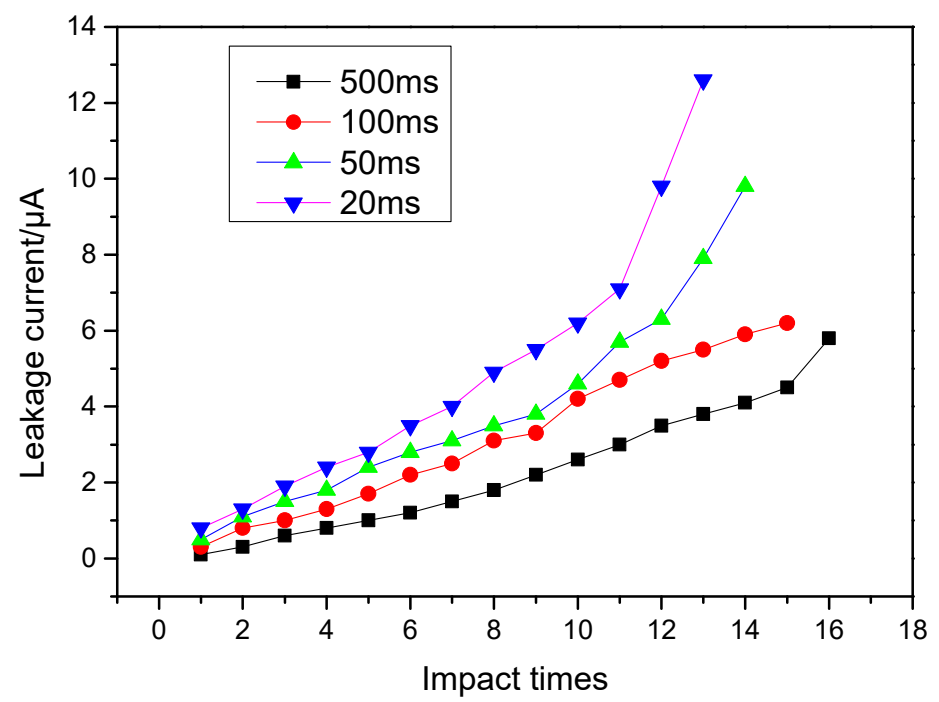

Figure 6. The relationship between the leakage current of $\mathrm{ZnO}$ varistors and the number of impacts at different pulse intervals.

Through the impulse test, the values of the varistor voltage and leakage current, measured before the sample was damaged by the pulse under three pulses and four pulses, are shown in Table 4 . The $\mathrm{ZnO}$ varistor sample can withstand 23 shocks when impacted under three pulses. The minimum varistor voltage before damage is $634 \mathrm{~V}$, and the maximum leakage current is $6.9 \mu \mathrm{A}$. The $\mathrm{ZnO}$ varistor sample can withstand 20 shocks when impacted under four pulses. The minimum varistor voltage before damage is $620 \mathrm{~V}$, and the maximum leakage current is $7.9 \mu \mathrm{A}$.

Table 4. The electrical parameters after the impulse with different number of pulses.

\begin{tabular}{cccc}
\hline No. & $\boldsymbol{n}$ & $\mathbf{U}_{\mathbf{1} \mathbf{~ m A}}(\mathrm{V})$ & $\boldsymbol{I}_{\mathbf{i e}}(\boldsymbol{\mu} \mathrm{A})$ \\
\hline P13 & 23 & 636 & 6.8 \\
P14 & 23 & 634 & 6.6 \\
P15 & 23 & 634 & 6.9 \\
P16 & 20 & 623 & 7.5 \\
P17 & 20 & 621 & 7.8 \\
P18 & 20 & 620 & 7.9 \\
\hline
\end{tabular}

Comparing the experimental data analysis, it can be seen that due to the reduction of the number of pulses, the energy injected by the varistor is significantly reduced, and the number of shock resistances under three pulses and four pulses is significantly higher than that of five pulses. The relationship between the leakage current of $\mathrm{ZnO}$ varistors with different pulse numbers and the number of impacts is shown in Figure 7. As can be seen from the figure, the leakage current under three pulses, four pulses and five pulses all increase with the number of impacts. Under the same conditions, the greater the number of pulses, the faster the rate of change of the leakage current of the $\mathrm{ZnO}$ varistor. Under the same number of impacts, the greater the number of pulses, the greater the leakage current. The failure is the first to be reached under five pulses, and the corresponding leakage current value is also the largest. This shows that the aging rate is positively correlated with the number of pulses under multiple pulses. 


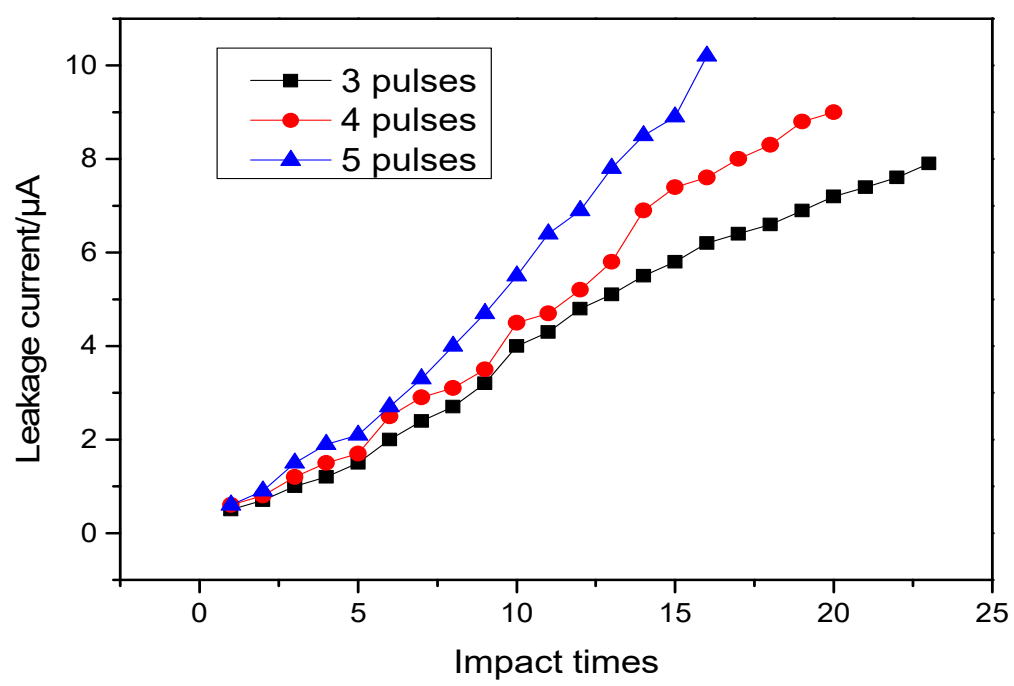

Figure 7. Relationship between the leakage current of $\mathrm{ZnO}$ varistors and the impact times under different pulse numbers.

\subsection{Relationship between Different Waveform Parameters and Temperature Rise of $\mathrm{ZnO}$ Varistor}

The three-dimensional distributions of the average temperature rise of $\mathrm{ZnO}$ varistor under three pulses, four pulses and five pulses are shown in Figures 8-10. The left horizontal axis is the number of impacts, the right horizontal axis is the pulse interval and the vertical axis is the average temperature rise of the surface of the $\mathrm{ZnO}$ varistor. Each point on the curved surface in the figure corresponds to the average surface temperature rise at different impact times and pulse intervals.

The average temperature rise of the surface of $\mathrm{ZnO}$ varistor under three pulses varies with the number of impacts and the pulse interval, as shown in Figure 8. The average temperature rise can reach up to $135^{\circ} \mathrm{C}$. After fitting, the relationship between the temperature under three pulses and the number of impacts and the pulse interval is as follows:

$$
Z_{3 p}=1.579 n-0.1132 \Delta t-0.05041 n^{2}+117.5
$$

where $\mathrm{Z}_{3 \mathrm{p}}$ is the average surface temperature rise of the $\mathrm{ZnO}$ varistor under three pulses, $n$ is the number of impacts and $\Delta t$ is the pulse interval.

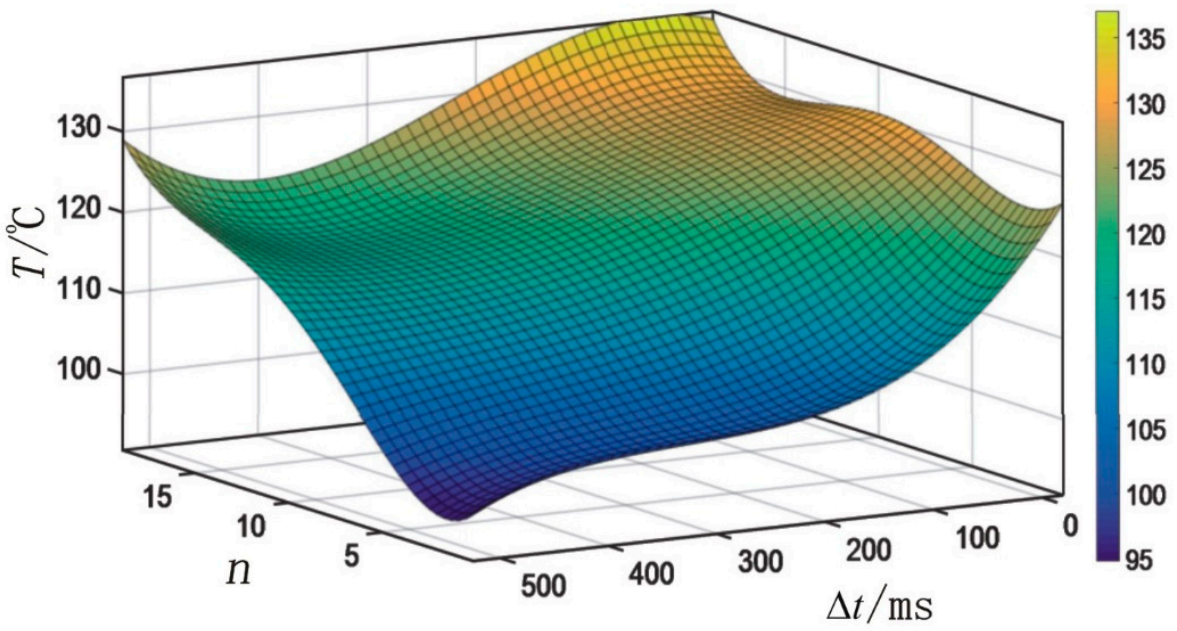

Figure 8. Average temperature rise of the $\mathrm{ZnO}$ varistor surface under three pulses. 
The change of the average temperature increase of the surface of the $\mathrm{ZnO}$ varistor under four pulses with the number of impacts, and the pulse interval is shown in Figure 9. The average temperature rise can be up to $140{ }^{\circ} \mathrm{C}$. After fitting, the relationship between the temperature under four pulses and the number of impacts and the pulse interval is as follows:

$$
Z_{4 p}=3.619 n-0.07714 \Delta t-0.1113 n^{2}+115.2
$$

where $Z_{4 p}$ is the average surface temperature rise of the $\mathrm{ZnO}$ varistor under four pulses, $n$ is the number of impacts and $\Delta t$ is the pulse interval.

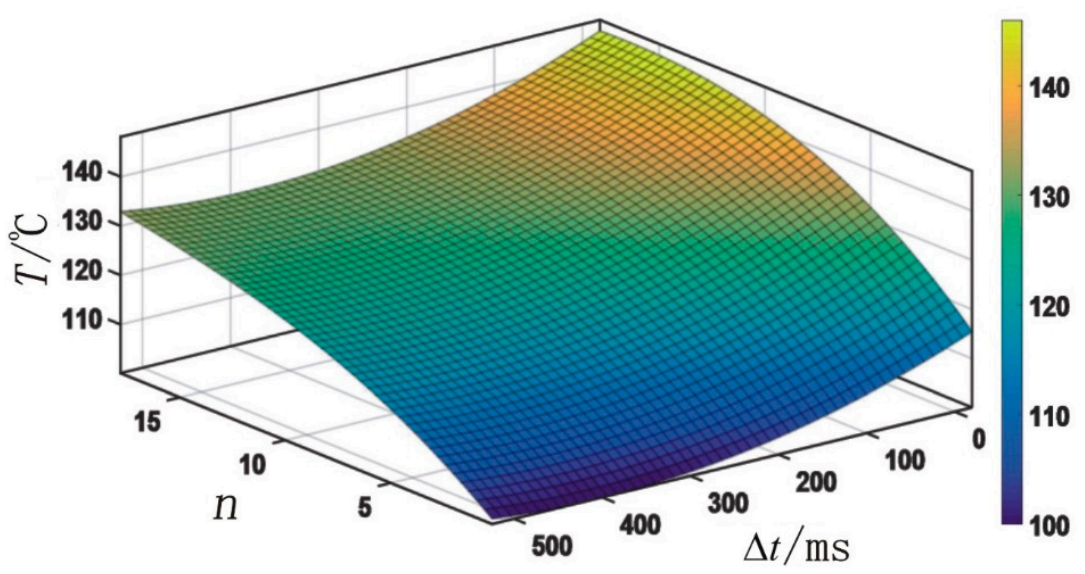

Figure 9. Average temperature rise of the $\mathrm{ZnO}$ varistor surface under four pulses.

The change of the average temperature rise of the surface of the $\mathrm{ZnO}$ varistor under five pulses with the number of impacts and pulse intervals is shown in Figure 10, and the average temperature rise can be up to $155^{\circ} \mathrm{C}$. After fitting, the relationship between the temperature and the number of impacts and pulse intervals under five pulses is:

$$
Z_{5 p}=3.73 n-0.07701 \Delta t-0.1196 n^{2}+129.9
$$

where $\mathrm{Z}_{5 \mathrm{p}}$ is the average surface temperature rise of the $\mathrm{ZnO}$ varistor under five pulses, $n$ is the number of impacts and $\Delta t$ is the pulse interval.

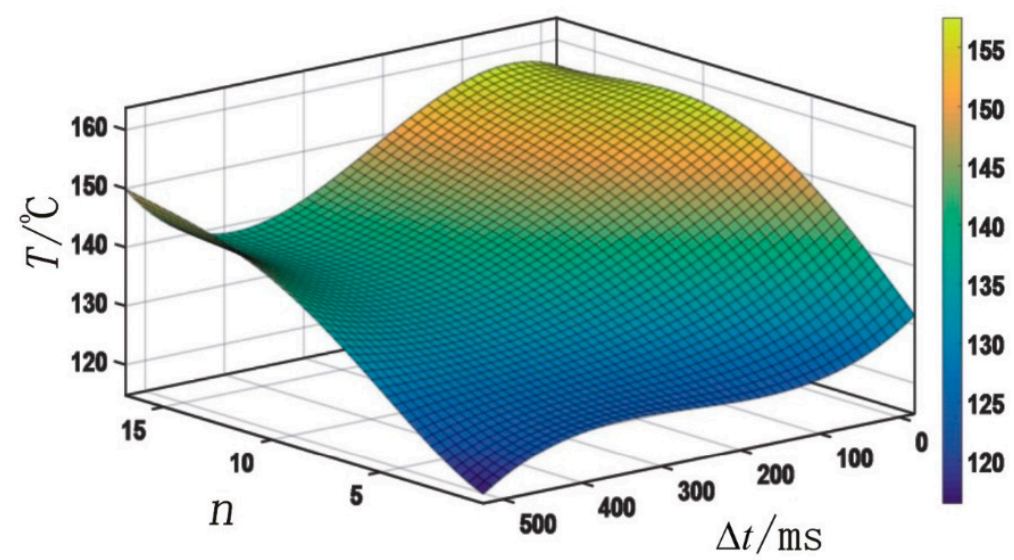

Figure 10. Average temperature rise of the $\mathrm{ZnO}$ varistor surface under five pulses.

It can be seen from the temperature rise distribution graph that, no matter what the number of pulses is, when the pulse interval is fixed, the surface temperature of the sample gradually increases with the increase of the number of impacts, but the rate of temperature increase in the late stage of 
impact is lower than that in the early stage of impact. Under the same conditions, the smaller the pulse interval, the greater the temperature rise value, and the pulse interval has a great influence on the temperature rise. Comparing the overall temperature rise of three pulse, four pulse and five pulse, it can be seen that the more pulses, the higher the average temperature rise. As the number of pulses increases, the average temperature rise of the surface of the $\mathrm{ZnO}$ varistor has a nonlinear relationship with the number of pulses. This is because heat will be dissipated in the pulse interval, and the accumulation of energy is not a simple summation.

When the temperature rise of the $\mathrm{ZnO}$ varistor reaches a certain level, serious thermal instability will occur. If the heat accumulation is too large in a short time, or the accumulated heat cannot be dissipated in time, it will cause the $\mathrm{ZnO}$ varistor to heat damage. Therefore, the greater the number of pulses and the smaller the pulse interval, the more likely that the $\mathrm{ZnO}$ varistor will be thermally damaged.

An infrared imager was used to scan the surface of the $\mathrm{ZnO}$ varistor sheet immediately after the impact, to obtain a thermographic image of the surface temperature distribution of the $\mathrm{ZnO}$ varistor. Figure 11 shows the surface temperature distribution of the $\mathrm{ZnO}$ varistor at different pulse numbers at $50 \mathrm{~ms}$ intervals. The thermal imaging images use different color reaction temperature values. The white bright area represents the high temperature area. It can be seen that, no matter how many pulses, $\mathrm{ZnO}$ The temperature distribution on the surface of the varistor is non-uniform, and the greater the number of pulses, the more non-uniform the temperature distribution. The temperature gradient is caused by the non-uniform material of the $\mathrm{ZnO}$ varistor.

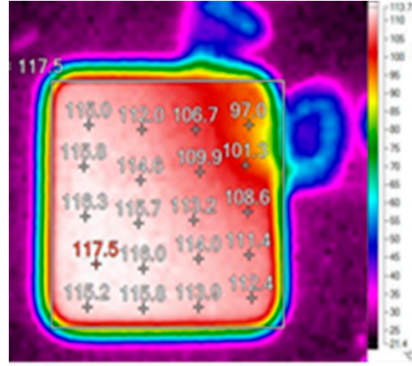

(a)

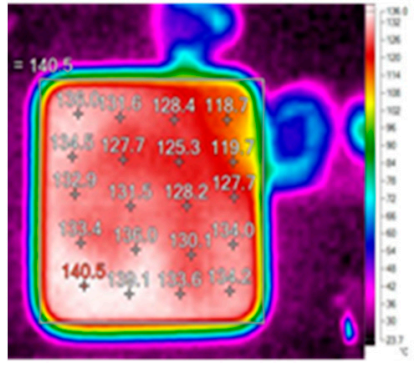

(b)

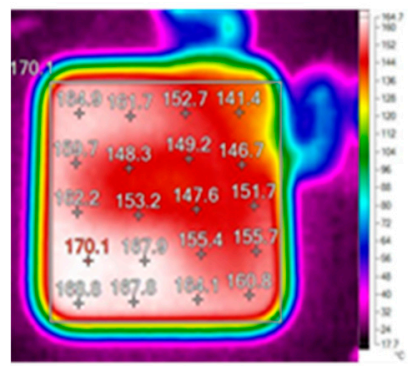

(c)

Figure 11. Surface temperature distribution of $\mathrm{ZnO}$ varistor under different pulse numbers. (a)Three pulses; (b) four pulses; (c) five pulses.

Statistical analysis of the sample surface temperature value, the sample surface temperature comparison under different pulse numbers is shown in Figure 12, the blue curve represents the maximum temperature $T_{\max }$, the black curve represents the minimum temperature $T_{\min }$, the red curve represents the average temperature Tav. It can be seen from the figure that as the number of pulses increases, the values of $\mathrm{T}_{\max }, \mathrm{T}_{\min }$, and $\mathrm{T}_{\mathrm{av}}$ all increase. Under three pulses, the maximum temperature of the sample surface is around $117^{\circ} \mathrm{C}$. Under four pulses, the maximum temperature of the sample surface is around $140{ }^{\circ} \mathrm{C}$. Under five pulses, the maximum surface temperature of the sample is around $170{ }^{\circ} \mathrm{C}$. As the number of pulses increases, the maximum temperature $T_{\max }$ increases the most. The average temperature has a linear relationship with the number of pulses, but the relationship between the maximum temperature $T_{\max }$ and the minimum temperature $T_{\min }$ and the number of pulses is nonlinear. It can be seen that the injected energy has a linear relationship with the number of pulses. The more pulses, the higher the average temperature. This is precisely due to the uniformity of the varistor, and the greater the number of pulses, the greater the effect of structural non-uniformity on the non-uniform temperature rise distribution. 


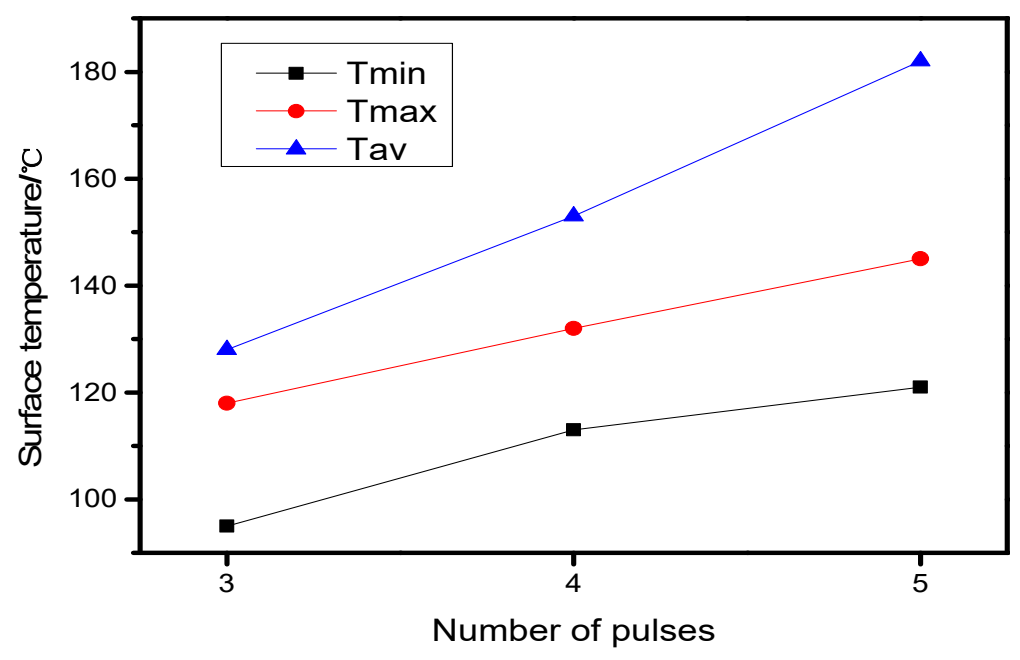

Figure 12. Comparison of the sample surface temperature under different pulse numbers.

\subsection{Aging Mechanism Based on Energy Absorption}

When the lightning current passes through the $\mathrm{ZnO}$ varistor, it must absorb energy itself when discharging the lightning current and suppressing transient overvoltage, that is, the injected energy is greater than the absorbed energy. The residual voltage is an important parameter that reflects the overvoltage protection level of the $\mathrm{ZnO}$ varistor, which is the maximum peak voltage between the two ends when the nominal current flows through the $\mathrm{ZnO}$ varistor. Therefore, the current waveform and residual voltage waveform after the lightning current impact should be collected, and the current and residual voltage data should be used as the calculation basis for energy absorption.

The impulse current and residual voltage waveform of the $\mathrm{ZnO}$ varistor under the action of a single $8 / 20 \mu$ s pulse waveform are shown in Figure 13. The red waveform is the current waveform, and the blue waveform is the residual voltage waveform when the applied impulse current is $20 \mathrm{kA}$. The value of residual voltage after impact is $1.32 \mathrm{kV}$. In the main part of the impulse current flow, the $8 / 20 \mu$ s current wave is a nonlinear wave, and the residual voltage wave can be approximately linearly decreasing.

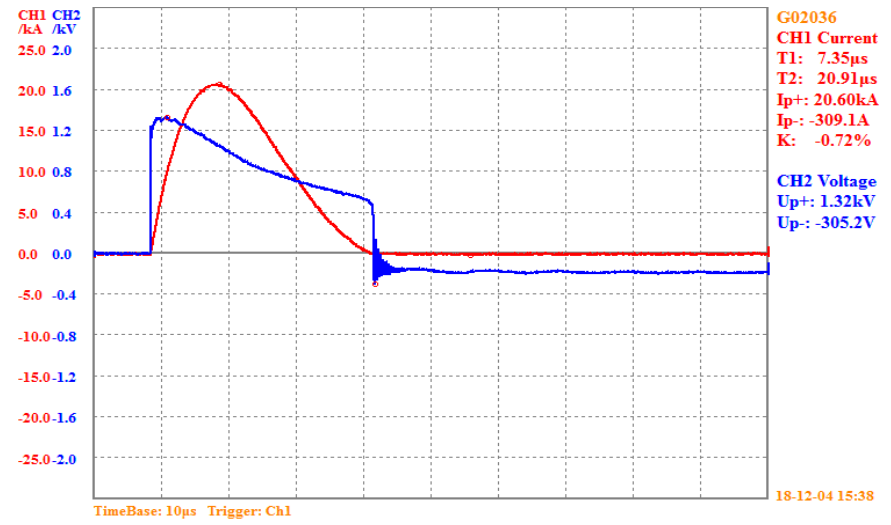

Figure 13. Waveform of current and residual voltage of $\mathrm{ZnO}$ varistor under a single 8/20 $\mu$ s pulse.

The $8 / 20 \mu$ s current wave can be expressed by power exponent:

$$
i(t)=A I_{\mathrm{m}} t^{3} \mathrm{e}^{-\frac{1}{\tau}}
$$

where $I_{\mathrm{m}}$ is the peak current, unit kA, A and $\tau$ is the fitting constant. $\mathrm{A}=0.1243 \mu \mathrm{s}^{-3}, \tau=3.91 \mu \mathrm{s}$. 
The residual pressure wave can be approximated as a linear decreasing function expressed as:

$$
v(t)=\left(\frac{V_{\min }-V_{\max }}{T}\right) t+V_{\max }
$$

where $V_{\max }$ is the maximum residual voltage in the figure, the unit is $\mathrm{kV}, V_{\min }$ is the minimum residual voltage in the figure, the unit is $\mathrm{kV}$ and $T$ is the time when the positive residual voltage in the figure is minimum.

The energy $W$ received by the $\mathrm{ZnO}$ varistor during the entire current wave time is usually determined by the actual voltage and current of the $\mathrm{ZnO}$ varistor through the lightning current, that is:

$$
W=\int_{0}^{T} v(t) i(t) \mathrm{d} t
$$

Substituting Equations (4)-(6), we get:

$$
\begin{gathered}
W=\int_{0}^{T}\left[A I_{\mathrm{m}}\left(\frac{V_{\min }-V_{\max }}{T}\right) t^{4} \mathrm{e}^{-\frac{1}{\tau}}+A I_{\mathrm{m}} V_{\max } t^{3}\right] \mathrm{d} t \\
\mathrm{a}=A I_{\mathrm{m}}\left(\frac{V_{\text {min }}-V_{\max }}{T}\right), \mathrm{b}=A I_{\mathrm{m}} V_{\max }
\end{gathered}
$$

when $T=30$, we get:

$$
W=19402 a+1330 b
$$

Under multi-pulse, the pulse interval of $50 \mathrm{~ms}$ can be approximated as an adiabatic process. In an ideal state, if the current amplitude and residual voltage under each pulse are the same, the energy sustained by the $\mathrm{ZnO}$ varistor under multi-pulse current is the same amplitude The corresponding multiple of the energy of the single pulse current wave is linear. However, the experimental results show that in a complete multi-pulse shock process, the impact current amplitude and residual voltage value of each pulse displayed on the oscilloscope are different. Therefore, the energy sustained by the $\mathrm{ZnO}$ varistor under multi-pulse current energy of a single pulse current wave at the same amplitude is not linear. This is because, during the actual impact, the energy accumulation causes the starting temperature of the next pulse to be higher than the temperature at the impact of the previous pulse. Figure 14 shows the current waveform and residual voltage waveform collected on the oscilloscope under five pulses, respectively. The five vertical lines in the figure above represent five pulses. The green box is the corresponding pulse sequence, and the green box is the first pulse, and the red ellipses are the other four pulses in a group of shocks. The lower waveform in the figure is an enlarged display of the waveform in the green box, where the yellow waveform is the current waveform and the blue waveform is the residual voltage waveform. 


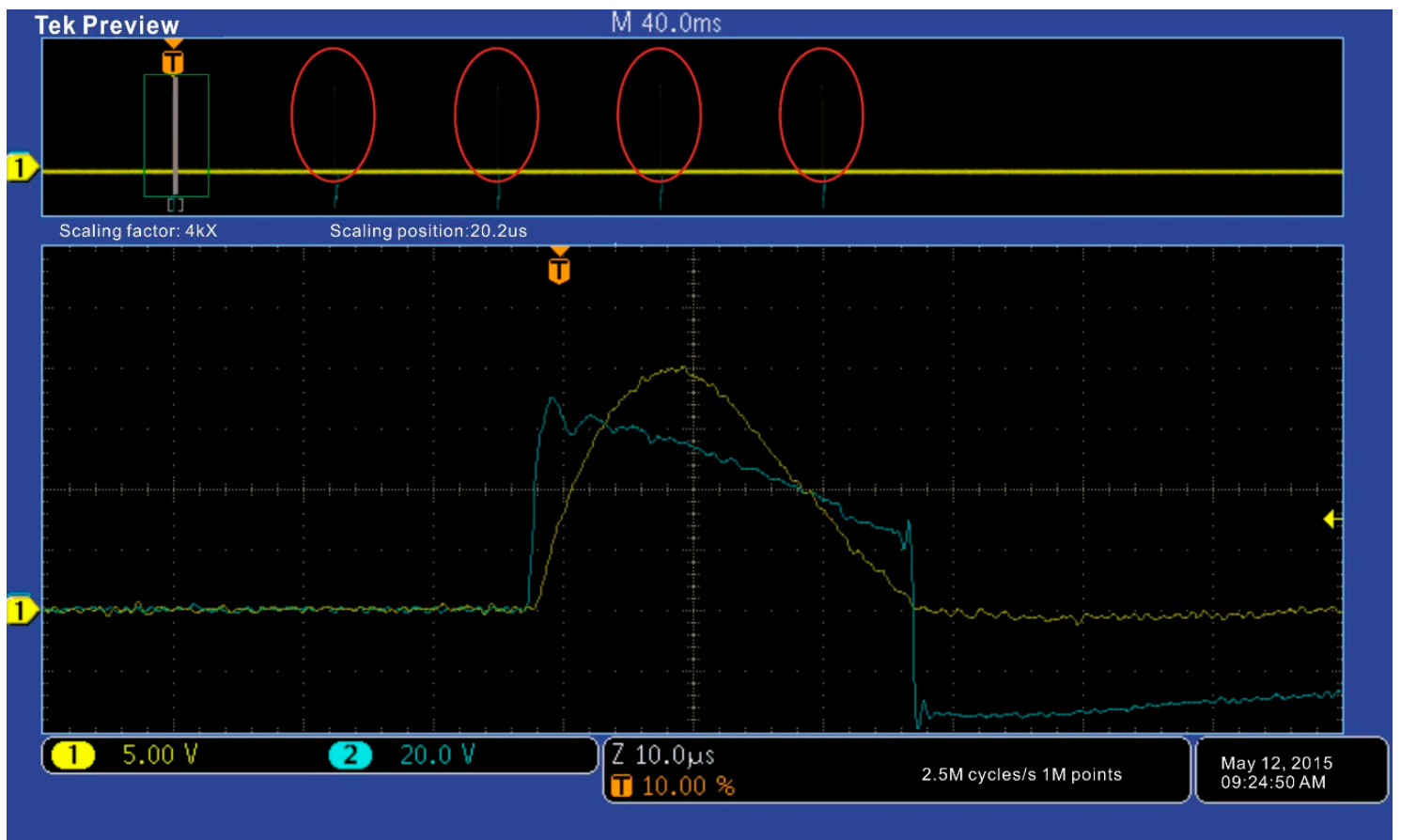

Figure 14. Current and voltage waveforms under five pulses.

Taking the current amplitude and residual voltage value of each pulse waveform acting on the $\mathrm{ZnO}$ varistor as energy calculation parameters, calculating the energy value under the action of each pulse, adding up the energy of five single pulses, according to the obtained impulse current and residual voltage waveforms, the five pulse current impulse results under $20 \mathrm{kA}$ conditions can be obtained. As shown in Table 5, the energy absorbed by the $\mathrm{ZnO}$ varistor under the action of the 5-pulse current is:

$$
W_{5 p}=19402\left(a_{1}+a_{2}+a_{3}+a_{4}+a_{5}\right)+1330\left(b_{1}+b_{2}+b_{3}+b_{4}+b_{5}\right)
$$

Substituting the impact result of the five pulse current in the table into Equation (9), the five pulse absorption energy is $1664.94 \mathrm{~J}$.

Table 5. Impact energy of the sample under five pulses.

\begin{tabular}{ccccccc}
\hline $\boldsymbol{n}$ & $\boldsymbol{V}_{\max }$ & $\boldsymbol{V}_{\min }$ & $\boldsymbol{I}_{\mathbf{m}}$ & $\mathbf{a}$ & $\mathbf{b}$ & $\boldsymbol{W} / \mathbf{J}$ \\
\hline 1st pulse & 1.35 & 0.71 & $19.48 \mathrm{kA}$ & -0.0051 & 0.3268 & 329.60 \\
2nd pulse & 1.37 & 0.68 & $19.62 \mathrm{kA}$ & -0.0052 & 0.3219 & 327.22 \\
3rd pulse & 1.38 & 0.65 & $19.70 \mathrm{kA}$ & -0.0059 & 0.3379 & 334.93 \\
4th pulse & 1.40 & 0.63 & $19.83 \mathrm{kA}$ & -0.0063 & 0.3450 & 336.62 \\
5th pulse & 1.42 & 0.60 & $19.88 \mathrm{kA}$ & -0.0067 & 0.3508 & 336.57 \\
\hline
\end{tabular}

Similarly, the impact energy values of the three pulse current and the four pulse current are also calculated according to the above energy accumulation method. The energy absorbed by three pulses is $991.75 \mathrm{~J}$, and the energy absorbed by four pulses is $1328.37 \mathrm{~J}$.

Taking five pulses as an example, the impact energy accumulation of $\mathrm{ZnO}$ varistor under different pulse sequences is shown in Figure 15. The number on the horizontal axis in Figure 15 represents the pulse sequence number within a shock period. For example, 1 represents the first pulse. The energy accumulation from the first pulse to the fifth pulse can be obtained. After each pulse is applied, the energy gradually increases and there is a cumulative effect of energy superposition. Except for the first pulse, the temperature of each subsequent pulse current injection is close to the temperature after the previous end. At this time, the $\mathrm{ZnO}$ varistor is subjected to 5 different temperature gradient thermal 
stresses.It can be seen that the temperature of the $\mathrm{ZnO}$ varistor gradually rises during the entire impact cycle and is subjected to multiple "short strikes" of thermal stress in consecutive short intervals. At this time, the Schottky barrier height must fall faster than the single pulse. As a result, the breakdown voltage of the grain boundary drops faster. In the later stage of the impact, the electrical properties of the sample are mainly controlled by the thermal destruction of the grain and the grain boundary. The varistor characteristic of the sample disappears, causing the local temperature of the sample to rise sharply, causing the sample to burst and damage. To sum up, the energy superimposed cumulative effect of multi-pulse impact accelerates the aging process of the $\mathrm{ZnO}$ varistor, and eventually produces irreversible structural damage.

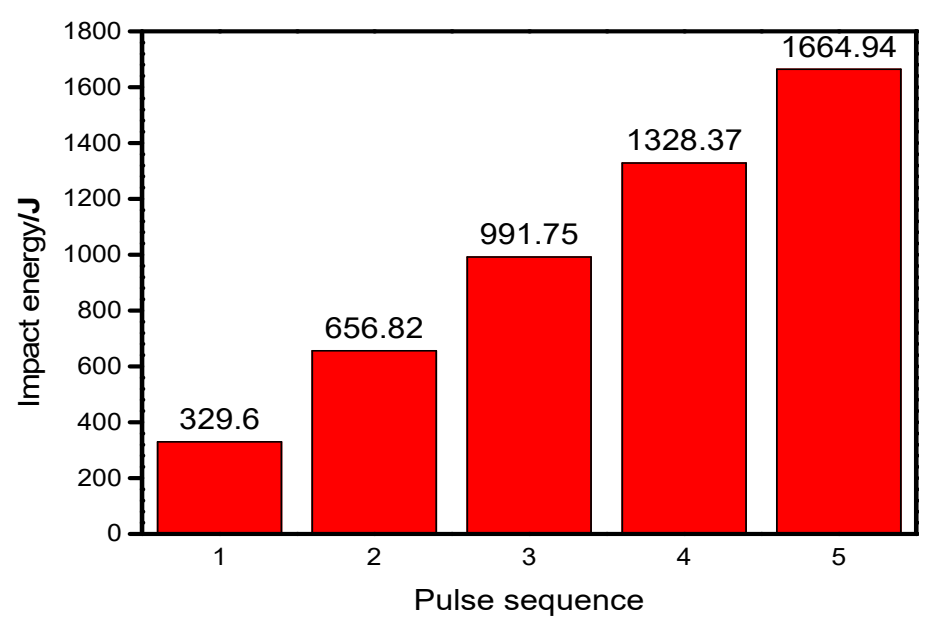

Figure 15. Current and voltage waveforms under five pulses.

\subsection{Heat Transfer Modelling}

In the impact process of the $8 / 20$ single pulse current wave, since the action time is very short, it can be considered that the interior of the varistor is insulated. However, in the case of multiple pulses, the problem of heat transfer should be considered, because there is heat conduction during the intermittent time of two adjacent pulses. The heat generated by the first pulse after the heat exchange between the heat dissipation, and the surrounding air during the intermittent time, is lower than that at the end of the first pulse, and this temperature is used as the initial temperature of the resistance during the second pulse. The temperature can be calculated by analogy.

According to the temperature distribution of the varistor thermal imaging, there are always weak points with relatively large current density and relatively high temperature inside the varistor. The destruction of the resistor starts from the weak point, assuming there is a small cylinder inside the varistor. Its equivalent resistance under high current is lower than the rest of the varistor. Next, the temperature variation of the varistor under a certain number of impacts will be simulated and calculated.

In the interval time of two adjacent pulse currents, the heat conduction inside the varistor can be described by the following equation in one-dimensional cylindrical coordinates:

$$
\frac{\partial^{2} T}{\partial r^{2}}+\frac{1}{r} \frac{\partial T}{\partial t}=\frac{c_{\mathrm{p}} \rho}{k} \frac{\partial T}{\partial t}
$$

where $k$ is the thermal conductivity, $c_{\mathrm{p}}$ is the heat capacity under constant pressure, $\rho$ is the specific gravity and $r$ is the radial distance from the center. The surface heat transfer at the side surface can be expressed as:

Boundary conditions:

$$
-k \frac{\partial T}{\partial r}=\alpha\left(T-T_{\alpha}\right) r=R
$$


where $\alpha$ is the comprehensive heat transfer coefficient of the surface. At room temperature of $20^{\circ} \mathrm{C}$, $\alpha=7.0, T_{\mathrm{a}}$ is the ambient temperature, and $R$ is the width of the varistor. Here, the finite difference method is used for calculation.

$$
\begin{gathered}
\frac{T_{\mathrm{i}}^{\mathrm{n}}-2 T_{\mathrm{i}+1}^{\mathrm{n}}+T_{\mathrm{i}+2}^{\mathrm{n}}}{\Delta r^{2}}+\frac{T_{\mathrm{i}+1}^{\mathrm{n}}-T_{\mathrm{i}}^{\mathrm{n}}}{i \Delta r \Delta r}=\frac{c_{\mathrm{p}} \rho}{k} \cdot \frac{T_{\mathrm{i}+1}^{\mathrm{n}}-T_{\mathrm{i}}^{\mathrm{n}}}{\Delta t} \mathrm{i}=1 \\
\frac{T_{\mathrm{i}-1}^{\mathrm{n}}-2 T_{\mathrm{i}}^{\mathrm{n}}+T_{\mathrm{i}+1}^{\mathrm{n}}}{\Delta r^{2}}+\frac{T_{\mathrm{i}+1}^{\mathrm{n}}-T_{\mathrm{i}-1}^{\mathrm{n}}}{i \Delta r \Delta r}=\frac{c_{\mathrm{p}} \rho}{k} \cdot \frac{T_{\mathrm{i}+1}^{\mathrm{n}+1}-T_{\mathrm{i}}^{\mathrm{n}}}{\Delta t} \mathrm{i}=1,2 \ldots \mathrm{M}-1
\end{gathered}
$$

At the node on the boundary, $T_{\mathrm{i}+1}$ does not exist, but the finite difference equation of the node at the boundary can be obtained by the boundary condition. Set on the boundary to extend the heat conduction area by a distance $\Delta r$, so that there is a hypothetical node of temperature $T_{-(i-1)}$, then the heat conduction equation at the boundary node is:

$$
\frac{T_{\mathrm{i}-1}^{\mathrm{n}}-2 T_{\mathrm{i}}^{\mathrm{n}}+T_{-(\mathrm{i}-1)}^{\mathrm{n}}}{\Delta r^{2}}+\frac{T_{-(\mathrm{i}-1)}^{\mathrm{n}}-T_{\mathrm{i}-1}^{\mathrm{n}}}{R 2 \Delta r}=\frac{c_{\mathrm{p}} \rho}{k} \cdot \frac{T_{\mathrm{i}}^{\mathrm{n}+1}-T_{\mathrm{i}}^{\mathrm{n}}}{\Delta t}
$$

Using the central difference formula, the finite difference form of the boundary conditions is:

$$
-k \frac{T_{-(\mathrm{i}-1)}^{\mathrm{n}}-T_{\mathrm{i}-1}^{\mathrm{n}}}{2 \Delta r}=\alpha\left(T_{\mathrm{i}}^{\mathrm{n}}-T_{\mathrm{a}}\right)
$$

Combine the two equations above and get:

$$
\frac{T_{\mathrm{i}-1}^{\mathrm{n}}-2 T_{\mathrm{i}}^{\mathrm{n}}+\frac{2 \Delta t}{k} \alpha\left(T_{\mathrm{i}}^{\mathrm{n}}-T_{\alpha}\right)}{\Delta r^{2}}+\frac{\alpha\left(T_{\mathrm{i}}^{\mathrm{n}}-T_{\alpha}\right)}{k R}=\frac{{ }_{\mathrm{p}} \rho}{k} \cdot \frac{T_{\mathrm{i}}^{\mathrm{n}+1}-T_{\mathrm{i}}^{\mathrm{n}}}{\Delta t} \mathrm{i}=\mathrm{M}
$$

This is the heat conduction equation of the node located on the convection boundary. Combining Formulas (15)-(17), the temperature distribution of the varistor before the second pulse comes after the end of the first pulse can be obtained. The finite difference expression given above is to find the temperature $T_{i}^{n+1}$ at the $(n+1)$ th time step $(i=1,2, \ldots)$, based on the known temperature $T_{\mathrm{i}}^{\mathrm{n}}$ at the $n$th time step at the previous moment. $(\mathrm{i}=1,2, \ldots, \mathrm{M})$.

Discrete $8 / 20$ us current waveform into units with time step $\Delta t=0.4 \mu \mathrm{s}$, and in the interval time of $10 \mathrm{~ms}-500 \mathrm{~ms}$, the time step $\Delta t=0.5 \mathrm{~ms}$ used for heat conduction. According to the model description calculation, the results corresponding to the multi-pulse current shocks with interval times of $20 \mathrm{~ms}$, $50 \mathrm{~ms}, 100 \mathrm{~ms}$ and $500 \mathrm{~ms}$ are shown in Figure 16 as a, b, c and d, to indicate the relationship between the temperature and the impact time. The horizontal axis in the figure is the impact time, where period $A$ is the time from the beginning of the first pulse to the end of the first pulse, and the temperature rises from the initial room temperature at this time; period B is the time from the end of the first pulse to the start of the second pulse. During this time, the varistor heat dissipates and the temperature drops; period $C$ is when the second pulse begins to function until the end time, at which time the varistor temperature rises sharply. It can be seen from the figure that the shorter the intermittent time, the higher the initial temperature at the second pulse current. Due to the sensitivity of the current-voltage characteristics to temperature, the current is more concentrated, and the temperature at the end of the entire impact test is higher. This is also the reason why the varistor is most prone to aging when there is an impact with an intermittent time of $20 \mathrm{~ms}$.

The shorter the pulse interval, the higher the temperature rise of the varistor, which is consistent with the results obtained in the experiment. 


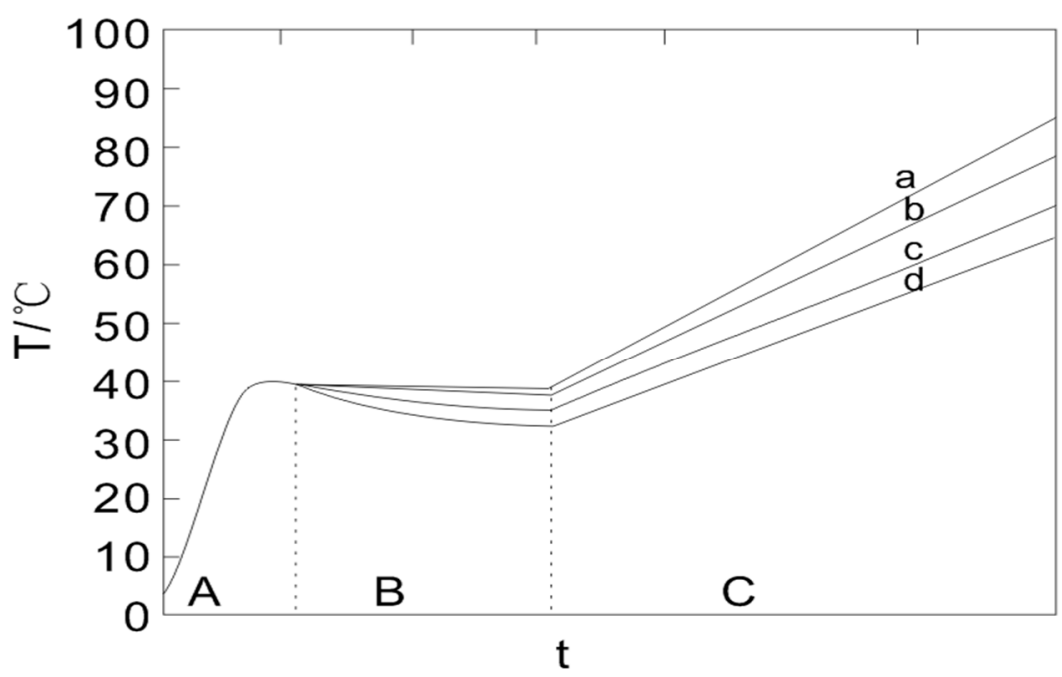

Figure 16. Variation of varistor temperature with impact time.

Taking the five pulse $50 \mathrm{~ms}$ interval as an example, the simulation calculation of temperature over time is performed. The calculation result is shown in Figure 17. The temperature rise after the action of each pulse can be obtained from the figure. It can be seen that the temperature and the number of pulses are non-linear.

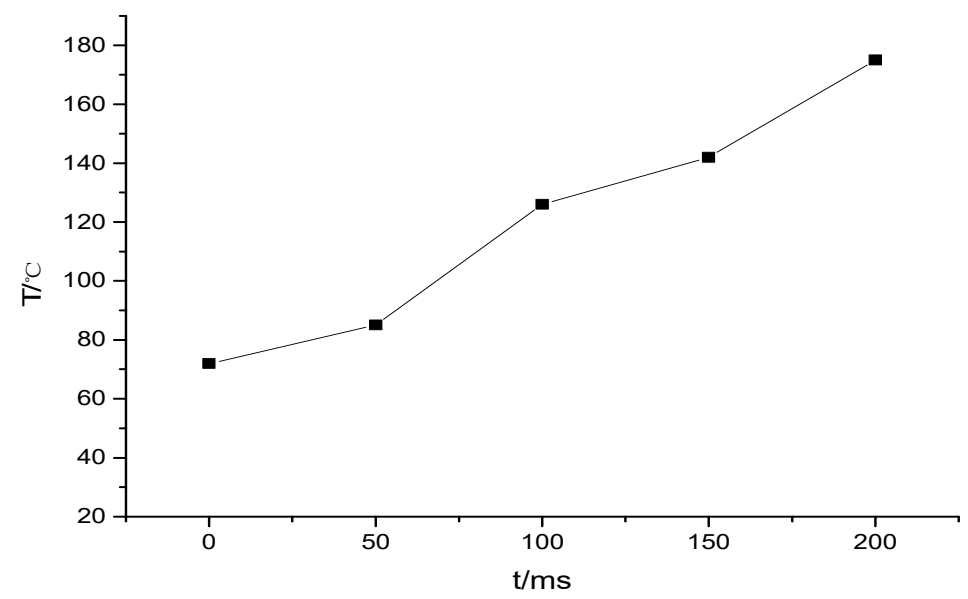

Figure 17. Variation of varistor temperature with impact time under the five pulse.

\section{Conclusions}

In this study, experiments were conducted to investigate the properties of $\mathrm{ZnO}$ varistors under multiple lightning impulse currents.

(1) The number of pulses and the pulse interval under multiple pulses play a decisive role in the aging rate. We analyzed the impact of pulse waveform parameters on aging. The more pulses and the smaller the pulse interval, the faster the aging speed of $\mathrm{ZnO}$ varistor, and the more likely there will be failure and damage.

(2) The temperature distribution on the surface of the $\mathrm{ZnO}$ varistor is non-uniform, and the greater the number of pulses, the more uneven the temperature distribution. The existing temperature gradient is caused by the uneven microscopic material of the $\mathrm{ZnO}$ varistor. The relationship between the average temperature rise and the number of shocks and pulse interval under different pulse numbers was established. The more the number of shocks and the smaller the pulse interval, the greater the temperature rise value. Comparing the overall temperature rise of three pulse, 
four pulse and five pulse, it can be seen that the more pulses, the higher the average temperature rise. As the number of pulses increases, the average temperature rise on the surface of the $\mathrm{ZnO}$ varistor has a nonlinear relationship with the number of pulses.

(3) The current amplitude and residual voltage value of each pulse waveform acting on the $\mathrm{ZnO}$ varistor are used as energy calculation parameters to calculate the energy value under the action of each pulse. The energy sustained by the $\mathrm{ZnO}$ varistor under multi-pulse current is not linearly related to the energy of the single-pulse current wave at the same amplitude. The superimposed cumulative energy of the impact under multi-pulse accelerates the aging process of the $\mathrm{ZnO}$ varistor and eventually produces an irreversible structural destruction.

(4) Heat transfer simulation results show that the shorter the pulse interval, the higher the temperature rise of the varistor, which is consistent with the results obtained in the experiment.

Author Contributions: Data curation, D.L.; Formal analysis, C.Z.; Investigation, C.L.; Methodology, D.L.; Project administration, C.Z. and H.X.; Software, C.L.; Supervision, H.Z. All authors have read and agreed to the published version of the manuscript.

Funding: This research was funded by the National Nature Science Foundation of China grant number 61671248 and The APC was funded by Heilongjiang Natural Fund Joint Guidance Project (LH2019E120).

Conflicts of Interest: The authors declare no conflict of interest.

\section{References}

1. Zhang, C. Research on the Aging and Deterioration of Surge Protectors in Low-Voltage Power Systems; Nanjing University of Information Science and Technology: Nanjing, China, 2013.

2. Su, Y.; Sun, L.; Yang, Z. Research progress of low voltage varistor. Electron. Compon. Mater. 2010, 29 , 74-78.

3. Yang, Z.; Chen, L. Analysis and application of capacitance change during the deterioration of zinc oxide varistor. High Volt. Technol. 2010, 36, 2167-2172.

4. Li, X.; Zhang, J.; Chen, L. Research on the design method of combined surge protector. Electr. Porcelain Light. Arrester 2017, 4, 16-22.

5. Yang, D.; Zhang, X.; Xu, Y. The failure mode and failure reason of SPD in low-voltage power supply system. Electr. Porcelain Arrester 2007, 4, 43-46.

6. Darveniza, M.; Tumma, L.R. Multipulse lightning currents and metal-oxide arresters. IEEE Trans. Power Deliv. 1997, 12, 1168-1175. [CrossRef]

7. Darveniza, M.; Mercer, D.R. Laboratory studies of the effects of multipulse lightning currents on distribution surge arresters. IEEE Trans. Power Deliv. 1993, 8, 1035-1044. [CrossRef]

8. Lee, B.-H.; Kang, S.-M. Properties of $\mathrm{ZnO}$ varistor blocks under multiple lightning impulse voltages. Curr. Appl. Phys. 2006, 6, 844-851. [CrossRef]

9. Lee, B.-H.; Kang, S.-M.; Pak, K.-Y.; Choi, H.S. Effect of multiple lightning impulse currents on Zinc oxide arrester blocks. In Proceedings of the 27th International Conference on Lightning Protection, Avignon, France, 13-16 September 2004; pp. 634-639.

10. Rousseau, A.; Zang, X.; Tao, M. Multiple shots on SPDs-Additional tests. In Proceedings of the 2014 International Conference on Lightning Protection (ICLP), Shanghai, China, 11-18 October 2014; pp. 997-1001.

11. Li, P.; Yang, Z.; Cao, H. Research on the aging performance of MOA under multi-pulse impact. China Electr. Power 2016, 49, 69-74.

12. Li, P.; Zhang, C.; Lv, D. The destruction form of metal oxide under multi-pulse lightning strike. High Volt. Technol. 2017, 43, 3792-3799.

13. Xiao, Y.; Yang, Z.; Liu, J. MOV performance of single-chip and double-chip in parallel under high-voltage multi-pulse impact. China Electr. Power 2016, 49, 55-59.

14. de Salles, C.; Martinez, M.L.B.; de Queiroz, Á.A.A. Ageing of metal oxide varistors due to surges. In Proceedings of the 2011 International Symposium on Lightning Protection (XI SIPDA), Fortaleza, Brazil, 3-7 October 2011; pp. 171-176. [CrossRef]

15. Vahidi, B.; Cornick, K.; Greaves, D. Effects of Multiple Stroke on ZnO Surge Arresters. In Proceedings of the 24th International Conference on Lightning Protection, Birmingham, UK, 14-18 September 1998; pp. 960-963. 
16. Heinrich, C.; Wagner, S.; Richter, B.; Kalkner, W. Multipulse tests on surge arresters for medium and low voltage systems. In Proceedings of the 24th International Conference on Lightning Protection, Birmingham, UK, 14-18 September 1998; pp. 790-794.

17. Haryono, T.; Sirait, K.T. The damage of $\mathrm{ZnO}$ arrester block due to multiple impulse currents. Telkomnika 2011, 9, 171. [CrossRef]

18. Haryono, T.; Sirait, K.T. Effect of multiple lightning strikes on the performance of ZnO lightning arrester block. High Volt. Eng. 2011, 37, 2763-2771.

19. Zhang, C.; Zhang, S. Zinc oxide nonlinear resistance impact aging failure mechanism. High Volt. Technol. $2000,5,48-49$.

(C) 2020 by the authors. Licensee MDPI, Basel, Switzerland. This article is an open access article distributed under the terms and conditions of the Creative Commons Attribution (CC BY) license (http://creativecommons.org/licenses/by/4.0/). 